\title{
Fabrication of Fe-6.5wt\%Si Ribbons by Melt Spinning Method on Large Scale
}

\author{
Y. F. Liang, S. Wang, H. Li, Y. M. Jiang, F. Ye, and J. P. Lin \\ State Key Laboratory for Advanced Metals and Materials, University of Science and Technology Beijing, \\ 30 Xueyuan Road, Beijing 100083, China
}

Correspondence should be addressed to Y. F. Liang; liangyf@skl.ustb.edu.cn

Received 6 November 2014; Accepted 31 December 2014

Academic Editor: Jianfei F. Sun

Copyright ( $\odot 2015$ Y. F. Liang et al. This is an open access article distributed under the Creative Commons Attribution License, which permits unrestricted use, distribution, and reproduction in any medium, provided the original work is properly cited.

Melt spinning method has been widely applied for fabrication of Fe-based amorphous/nanocrystalline ribbons in industry. Compared with Fe-based amorphous/nanocrystalline alloys, Fe-6.5wt\%Si high silicon steel is of low cost and has comparable excellent soft magnetic properties. Due to higher melting point and absence of supercooled liquid region, fabrication of $\mathrm{Fe}-6.5 \mathrm{wt} \% \mathrm{Si}$ ribbons is very hard and is only on lab scale. In this paper, we report that large scale fabrication of Fe- $6.5 \mathrm{wt} \% \mathrm{Si}$ ribbons was successful and microstructures, ordered structures, and mechanical and soft magnetic properties of the ribbons were investigated. Due to rapid solidification rate, the ribbons were of ultrafine grains, and low degree of order and exhibited some extent of bending and tensile ductility. After heat treatment, excellent soft magnetic properties were obtained. Due to near-zero magnetostriction, the ribbons are promising to be used in electric devices with high frequencies where low noises are required.

\section{Introduction}

Fe-6.5wt\%Si alloy has excellent soft magnetic properties [1], but it is very brittle at room temperature due to formation of ordered structures [2-4]. It is very hard to fabricate this alloy into thin sheet by conventional cold rolling method as cracks are easy to take place [5]. Warm and cold rolling method was developed to improve the ductility step by step during the process, but the whole process route was complex [68]. There are several other methods developed to avoid the room-temperature brittleness area, such as chemical vapor deposition (CVD) [9], spray forming [10, 11], direct powder rolling (DPR) [12], and dipping and diffusion annealing [13]. These methods have not succeeded in industry except JFE Super Cores produced by CVD process in Japan.

Rapid quenching from melt using single-roller has also been applied to produce $\mathrm{Fe}-6.5 \mathrm{wt} \% \mathrm{Si}$ alloy ribbons [1417]. Small samples with width $5 \sim 25 \mathrm{~mm}$ were successfully obtained. Microstructure and mechanical and magnetic properties were investigated. Due to the limited size of the ribbon, rapid quenching has not succeeded in industry. Compared with amorphous Fe-based ribbons, Fe-6.5wt\%Si alloy is much more difficult to be rapidly quenched into continuous ribbons. Limitation of both width and length of the ribbons hinders the application of the melt spinning method. In this paper, we report successful fabrication of wide and continuous ribbons fabricated by melt spinning from single-roller. Ordered structures have crucial effect on mechanical and magnetic properties of this alloy and are investigated thereby.

\section{Experimental}

Raw materials of Fe- $6.5 \mathrm{wt} \% \mathrm{Si}$ alloy were fabricated by melting electrolytic iron and metallic silicon together in a medium induction furnace in vacuum. For melt spinning, the alloy ingot was loaded in a quartz tube with a nozzle $30 \mathrm{~mm}$ long and melted by high-frequency induction heating. The molten alloy was ejected to a copper wheel with the aid of high pressure of argon in the quartz tube and the wide ribbons were formed with rapid solidification. A set of experimental conditions such as roller rotation speed, ejection pressure, and melting temperature were adjusted for production of continuous ribbons. Surfaces of the as-quenched ribbons were observed by scanning electron microscopy (SEM, Zeiss 


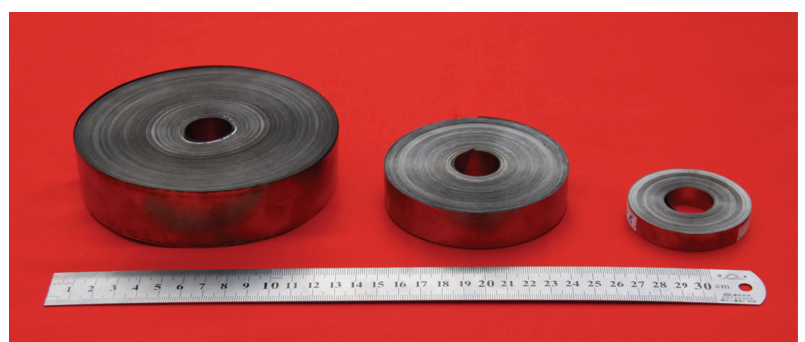

Figure 1: Melt spinning Fe-6.5wt\%Si ribbons of $30 \mu \mathrm{m}$ in thickness, with width of $30 \mathrm{~mm}, 20 \mathrm{~mm}$, and $10 \mathrm{~mm}$ from left to right.

SUPRA 55). Bending ductility was estimated by bending the ribbons to $180^{\circ}$ and the longitudinal microstructure of the ribbon after bending was observed by optical microscopy (OM, Ernst Leitz Wetzlar). Ordered structures of the asquenched ribbons were investigated by transmission electron microscopy (TEM, JEM-2010), for which a twin jet polishing in a solution of $90 \%$ glacial acetic acid and $10 \%$ perchloric acid was applied. A four-high mill was used for cold rolling of the as-quenched ribbons. Tensile tests were carried out using Instron 5969 tensile tester at room temperature with a strain rate of $10^{-3} \mathrm{~s}^{-1}$. AC magnetic properties were investigated followed by heat treatment of the as-quenched ribbon in vacuum and the $\mathrm{MgO}$ powder was used to prevent conglutination of the belt as reported previously [6].

\section{Results and Discussion}

The ribbons produced by single-roller melt spinning are shown in Figure 1, in which a continuous wound tape with $30 \mathrm{~mm}$ in height and $5 \mathrm{~kg}$ in weight is shown. The continuous ribbons have uniform edges, exhibiting good surface quality and metallic lustrous appearance. The thickness of the ribbons varies from 20 to $40 \mu \mathrm{m}$ mainly controlled by the distance from the nozzle to the $\mathrm{Cu}$ wheel when other parameters are fixed, such as the wheel speed, the air pressure, and the liquid temperature.

Direct observation of the surfaces of the as-quenched ribbons by SEM is shown in Figure 2. Ultrafine grains are obtained in the as-quenched ribbons, with diameters ranging from 0.5 to $5 \mu \mathrm{m}$. Due to the fast cooling and solidification rate, the crystal nucleation rate from the liquid is large, while the lateral growth of the crystals is prohibited.

The ribbons can be bent into certain shapes. No cracks are found in the bending area even after bending into $180^{\circ}$ as shown in Figure 3. The excellent bending ductility guarantees that the ribbons can be coiled into tapes.

The microstructure of the ribbons after quenching is shown in Figure 4. From the diffraction pattern, it is found that the $\mathrm{B} 2$ spots exist, although the intensity is faint, while the $\mathrm{DO}_{3}$ spots hardly exist. According to Figure 4(a), we can see that the formation of $\mathrm{B} 2$ ordered structure is hindered but not completely prohibited by rapid quenching, while, for $\mathrm{D}_{3}$, the ordering transformation is completely prohibited during the rapid solidification process. Due to the spallation from the $\mathrm{Cu}$ wheel after rapid quenching, the ribbons are bent and deformation takes place. In Figure 4(b), we can see that the super dislocations tangled and aligned.

Due to excellent ductility after rapid quenching, the ribbons can be cold rolled and the ribbons as-quenched and after cold rolling are shown in Figure 5, including surfaces of the ribbon, that is, the surface contacting $\mathrm{Cu}$ wheel and the free surface. After cold rolling, the roughness of the surface is improved, which is helpful to improve the lamination factor and thus the soft magnetic properties can be improved.

For the ribbons as-quenched and after cold rolling, the tensile engineering stress-strain curves are shown in Figure 6. It is found that the as-quenched ribbon exhibited excellent tensile ductility of about $1 \%$, which is very good for this brittle alloy. After cold rolling, the yield stress increases with increasing rolling reduction, while the ductility of the ribbon decreases. Due to work hardening, the yield stress increases and the ductility decreases drastically.

After heat treatment $\left(1100^{\circ} \mathrm{C} / 5 \mathrm{~h}\right.$, furnace cooling), AC magnetic properties of the ribbons are shown in Figure 7 in comparison with ultrathin sheet produced by cold rolling [6] and CVD [18] methods. It is found that, with the frequencies below $10 \mathrm{kHz}$, the core losses in this work are a little higher or as good as those produced by cold rolling and CVD process. With frequencies larger than $10 \mathrm{kHz}$, the iron losses are much lower than cold rolled or CVD sheet. The core losses of ribbons are crucial to the thickness of the ribbon and also to their microstructure. Thinner thickness is helpful to decrease eddy current loss at high frequencies, and the melt spinning ribbons are more suitable to be used in high frequencies.

With proper control of melt spinning process, continuous ribbons with uniform edges are fabricated, exhibiting good surface quality, and can be coiled into large tapes. The thickness of the ribbons varies from 20 to $40 \mu \mathrm{m}$, and the width of the ribbons is up to $30 \mathrm{~mm}$. Due to rapid cooling rate and thus rapid solidification rate, melt spinning ribbons are of ultrafine grains in lateral, with diameters ranging from 0.5 to $5 \mu \mathrm{m}$ as shown in Figure 2, while columnar grains are observed through the thickness of the ribbons, and the length could be $30 \mu \mathrm{m}$ as its thickness, as shown in Figure 3(b). Compared with the grain diameter of $10 \mathrm{~mm}$ for the $25 \mathrm{~kg}$ ingot, the grain size is decreased drastically. The rapid cooling rate is also helpful to hinder ordering transformations in this alloy. Room brittleness of this alloy is ascribed to the appearance of $\mathrm{B} 2$ and $\mathrm{D}_{3}$ ordered phases in this alloy [3,5]. At higher temperatures, the alloy is of A2 structure and is rather ductile to be hot rolled. Singleroller rapid quenching is helpful to hinder transformation from A2 to B2 and prohibit ordering transformation from $\mathrm{B} 2$ to $\mathrm{DO}_{3}$, for which transformations take place at $750^{\circ} \mathrm{C}$ and $600^{\circ} \mathrm{C}$, respectively [19]. As the brittleness is originating from the ordered structures in this alloy, especially from the mixture of $\mathrm{B} 2$ and $\mathrm{D}_{3}$ ordered structures, rapid quenching is helpful to improve the ductility. Bending and tensile experiments as shown in Figures 3, 5, and 6 indicate that the as-quenched ribbons have excellent room-temperature ductility and that the ribbons could be bent to $180^{\circ}$ without bending cracks, could be cold rolled to $35 \%$ in reduction, and could be plastically deformed by tension. The excellent ductility of the ribbons guarantees that the continuous rapidly 


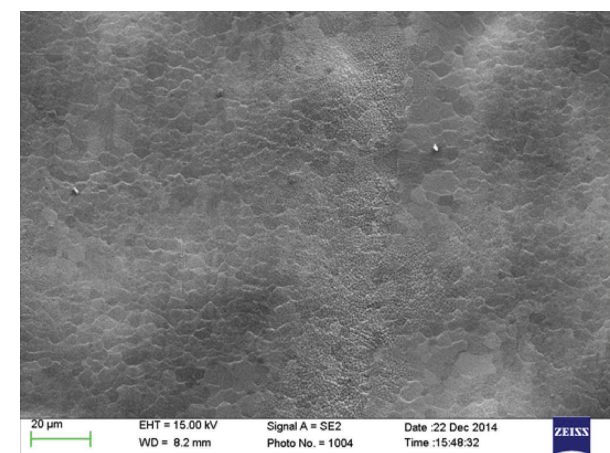

(a)

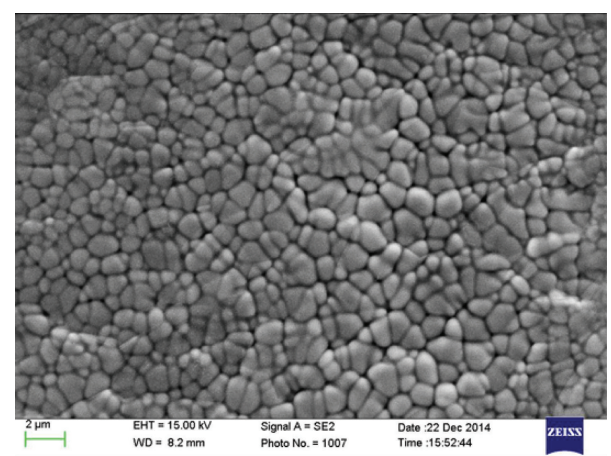

(b)

FIGURE 2: Surfaces of the ribbons after rapid quenching: (a) grain diameters of about $5 \mu \mathrm{m}$ and (b) grain diameters of about $0.5 \mu \mathrm{m}$.

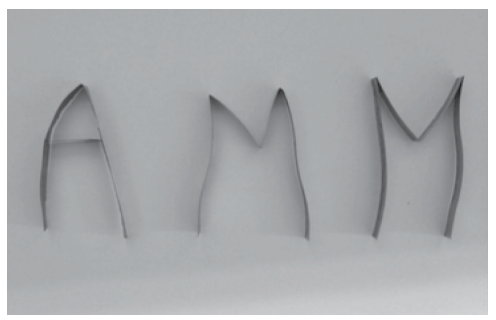

(a)

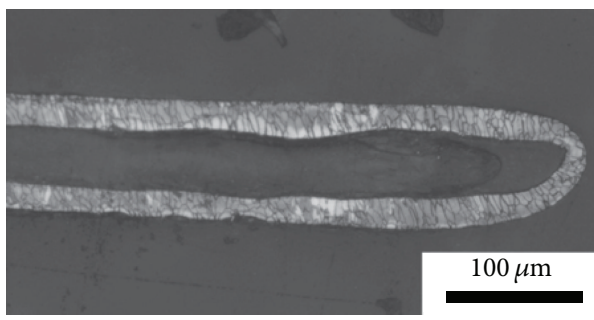

(b)

FIGURE 3: Rapidly quenched ribbons possess good bending ductility: (a) ribbons are bent into $180^{\circ}$ and (b) no cracks are found after bending.

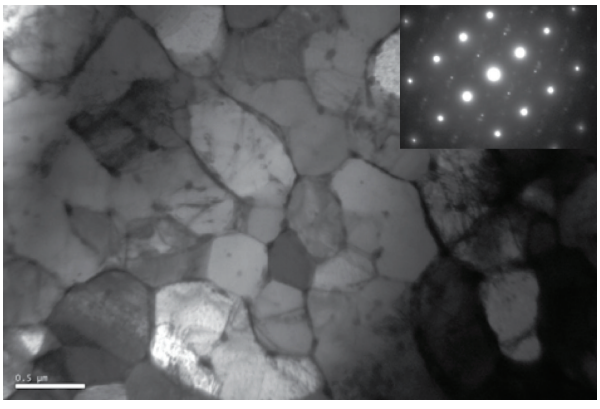

(a)

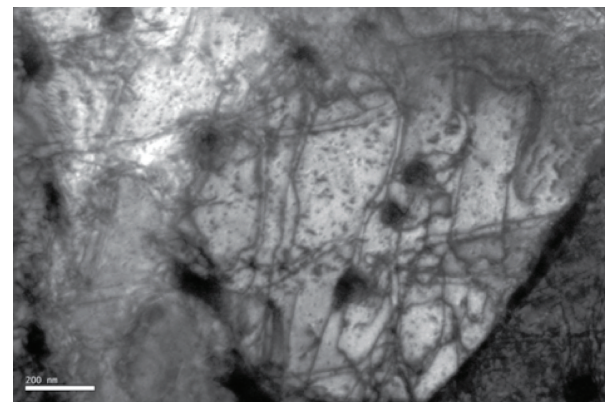

(b)

FIGURE 4: TEM of rapidly quenched ribbons: (a) bright field microstructure of the ribbon with diffraction pattern inset and (b) substructure of the ribbon showing super dislocations.

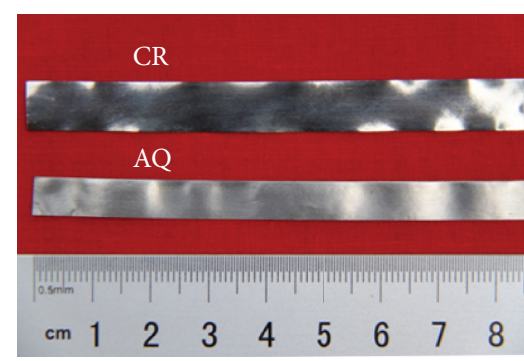

(a)

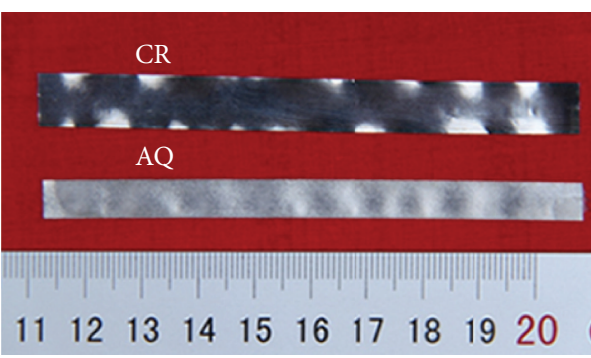

(b)

FIGURE 5: Rapidly quenched ribbons with and without cold rolling of 33\% reduction: (a) surface contacting the single-roller and (b) free surface of the ribbon. AQ: as-quenched, CR: cold rolled. 


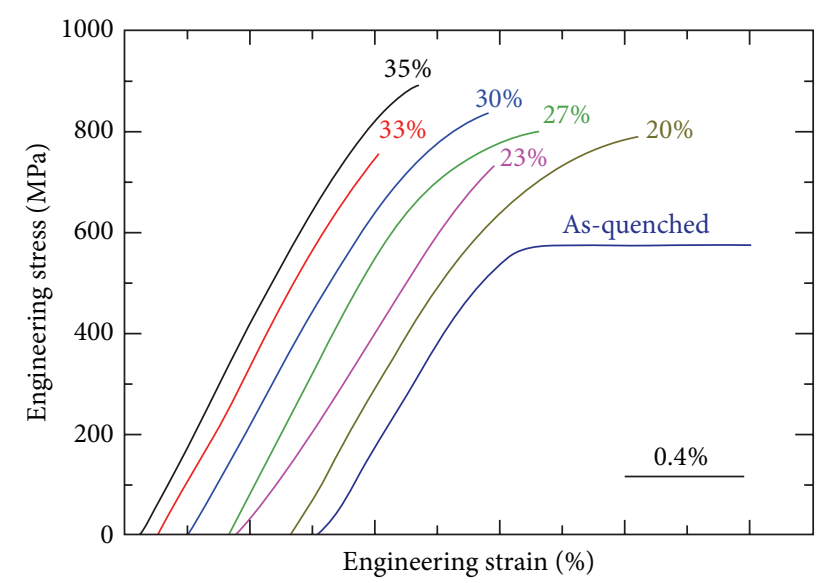

Figure 6: Tensile engineering stress-strain curves of as-quenched ribbon and ribbons with different cold rolling reduction.

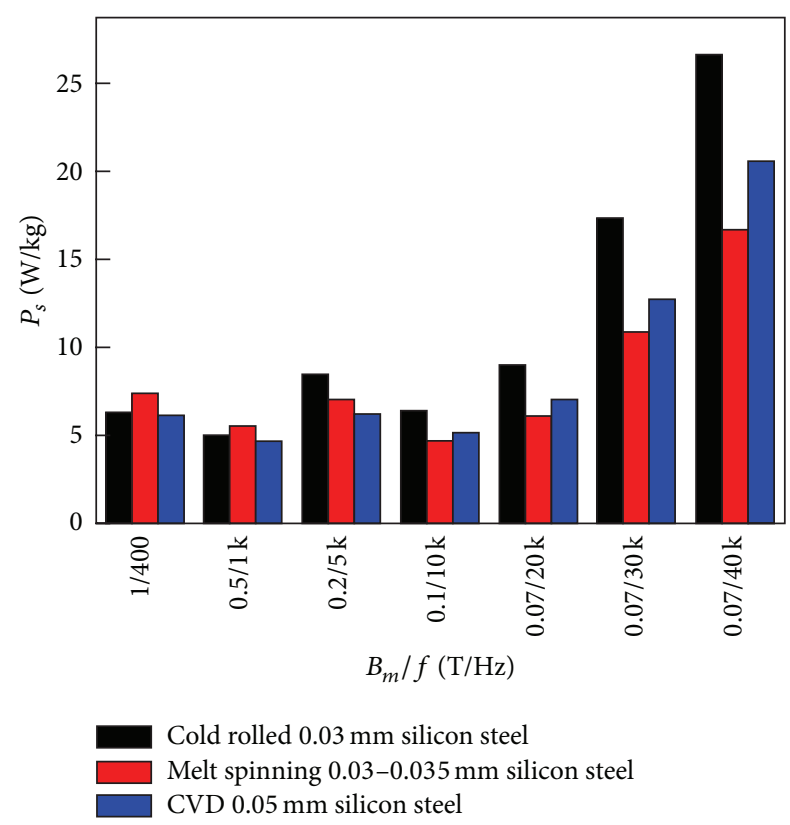

FIgURE 7: Core losses of rapidly quenched ribbons after heat treatment in comparison with cold rolled sheet and CVD sheet.

quenched ribbons could be coiled into tapes on large scale. After heat treatment, the rapidly quenched ribbons show as good soft magnetic properties as ultrathin sheet produced by cold rolling and CVD process and even better soft magnetic properties for higher frequencies up to $10 \mathrm{kHz}$.

\section{Conclusions}

(1) Fabrication of $\mathrm{Fe}-6.5 \mathrm{wt} \% \mathrm{Si}$ ribbons with $30 \mathrm{~mm}$ in width was successful using single-roller rapid quenching method. The continuous ribbons have uniform edges, exhibit good surface quality, and can be coiled into large scale tapes.
(2) Due to rapid solidification rate, ultrafine grains are obtained after melt spinning. Meanwhile, transformation of ordered structure B2 is hindered, and the ordered structure $\mathrm{DO}_{3}$ is prohibited. The as-quenched ribbons exhibit excellent bending and tensile ductility.

(3) After proper heat treatment, excellent AC magnetic properties can be obtained for as-quenched ribbons, comparable to ultrathin sheet fabricated by cold rolling or CVD process.

\section{Conflict of Interests}

The authors declare that there is no conflict of interests regarding the publication of this paper.

\section{Acknowledgments}

Financial support from the Major State Basic Research Development Program of China (973 Program, no. 2011CB606304), the Natural Science Foundation of China (no. 51301019), the Fundamental Research Funds for the Central Universities (no. FRF-TP-14-099A2), and the State Key Laboratory for Advanced Metals and Materials (no. 2014Z-23) is gratefully acknowledged.

\section{References}

[1] R. M. Bozorth, Ferromagnetism, D. Van Nostrand, New York, NY, USA, 1951.

[2] K. Raviprasad and K. Chattopadhyay, "The influence of critical points and structure and microstructural evolution in iron rich Fe-Si alloys," Acta Metallurgica et Materialia, vol. 41, no. 2, pp. 609-624, 1993.

[3] J. S. Shin, J. S. Bae, H. J. Kim et al., "Ordering-disordering phenomena and micro-hardness characteristics of B2 phase in Fe(5-6.5\%)Si alloys," Materials Science and Engineering A, vol. 407, no. 1-2, pp. 282-290, 2005.

[4] T. Ros-Yanez, D. Ruiz, J. Barros, Y. Houbaert, and R. Colás, "Study of deformation and aging behaviour of iron-silicon alloys," Materials Science and Engineering: A, vol. 447, no. 1-2, pp. 27-34, 2007.

[5] J.-S. Shin, Z.-H. Lee, T.-D. Lee, and E. J. Lavernia, "The effect of casting method and heat treating condition on cold workability of high-Si electrical steel," Scripta Materialia, vol. 45, no. 6, pp. 725-731, 2001.

[6] Y. F. Liang, F. Ye, J. P. Lin, Y. L. Wang, and G. L. Chen, "Effect of annealing temperature on magnetic properties of cold rolled high silicon steel thin sheet," Journal of Alloys and Compounds, vol. 491, no. 1-2, pp. 268-270, 2010.

[7] Y. F. Liang, F. Ye, J. P. Lin, Y. L. Wang, L. Q. Zhang, and G. L. Chen, "Effect of heat treatment on mechanical properties of heavily cold-rolled Fe-6.5wt\%Si alloy sheet," Science China Technological Sciences, vol. 53, no. 4, pp. 1008-1011, 2010.

[8] F. Ye, Y. F. Liang, Y. L. Wang, J. P. Lin, and G. L. Chen, "Fe$6.5 \mathrm{wt} \% \mathrm{Si}$ high silicon steel sheets produced by cold rolling," in Thermec 2009, T. Chandra, N. Wanderka, W. Reimers, and M. Ionescu, Eds., parts 1-4, pp. 1428-1433, Trans Tech, Zürich, Switzerland, 2010. 
[9] Y. Takada, M. Abe, S. Masuda, and J. Inagaki, "Commercial scale production of $\mathrm{Fe}-6.5 \mathrm{wt}$. \% Si sheet and its magnetic properties," Journal of Applied Physics, vol. 64, no. 10, pp. 5367-5369, 1988.

[10] M. C. A. Silva, C. Bolfarini, and C. S. Kiminami, "Microstructure and magnetic properties of Fe- $6.5 \mathrm{wt} \% \mathrm{Si}$ alloy obtained by spray forming process," Materials Science Forum, vol. 498-499, pp. 111-118, 2005.

[11] C. Bolfarini, M. C. A. Silva, A. M. Jorge Jr., C. S. Kiminami, and W. J. Botta, "Magnetic properties of spray-formed Fe- $6.5 \% \mathrm{Si}$ and $\mathrm{Fe}-6.5 \% \mathrm{Si}-1.0 \% \mathrm{Al}$ after rolling and heat treatment," Journal of Magnetism and Magnetic Materials, vol. 320, no. 20, pp. e653e656, 2008

[12] R. Li, Q. Shen, L. Zhang, and T. Zhang, "Magnetic properties of high silicon iron sheet fabricated by direct powder rolling," Journal of Magnetism and Magnetic Materials, vol. 281, no. 2-3, pp. 135-139, 2004.

[13] T. Ros-Yañez, Y. Houbaert, and V. Gómez Rodríguez, "Highsilicon steel produced by hot dipping and diffusion annealing," Journal of Applied Physics, vol. 91, no. 10, pp. 7857-7859, 2002.

[14] K.-I. Arai and N. Tsuya, "Ribbon-form silicon-iron alloy containing around 6.5 percent silicon," IEEE Transactions on Magnetics, vol. 16, no. 1, pp. 126-129, 1980.

[15] K. I. Arai, N. Tsuya, K. Ohmori, H. Shimanaka, and T. Miyazaki, "Rapidly quenched ribbon-form silicon-iron alloy with high silicon concentration," Journal of Magnetism and Magnetic Materials, vol. 15-18, no. 3, pp. 1425-1426, 1980.

[16] J. E. Wittig and G. Frommeyer, "Deformation and fracture behavior of rapidly solidified and annealed iron-silicon alloys," Metallurgical and Materials Transactions A, vol. 39, no. 2, pp. 252-265, 2008.

[17] R. K. Roy, A. K. Panda, M. Ghosh, A. Mitra, and R. N. Ghosh, "Effect of annealing treatment on soft magnetic properties of Fe-6.5 wt\% Si wide ribbons," Journal of Magnetism and Magnetic Materials, vol. 321, no. 18, pp. 2865-2870, 2009.

[18] Y. Tanaka, Y. Takada, M. Abe, and S. Masuda, "Magnetic properties of $6.5 \% \mathrm{Si}-\mathrm{Fe}$ sheet and its applications," Journal of Magnetism and Magnetic Materials, vol. 83, no. 1-3, pp. 375-376, 1990.

[19] H. Okamoto, Desk Handbook: Phase Diagrams for Binary Alloys, ASM International, Materials Park, Ohio, USA, 2000. 

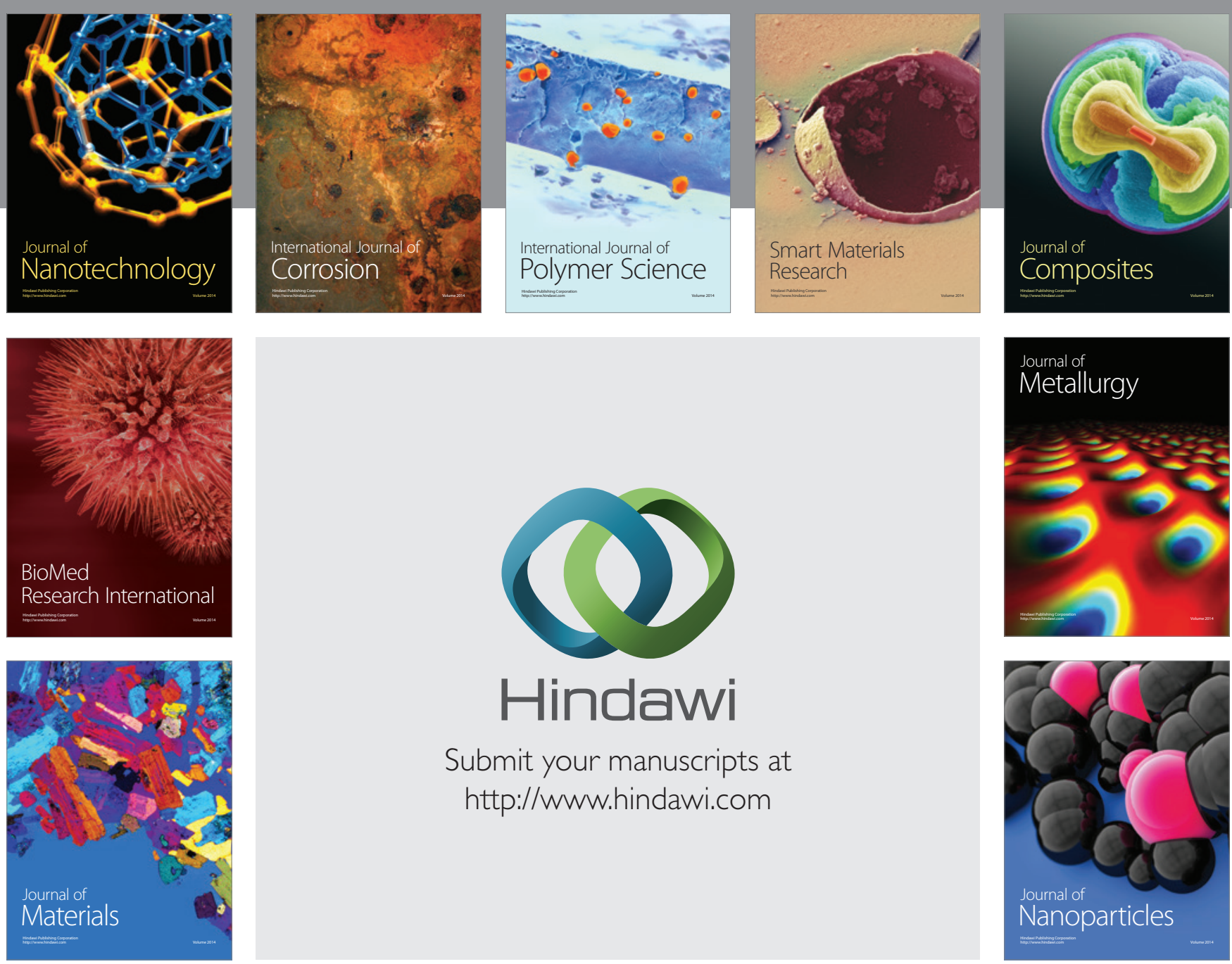

Submit your manuscripts at http://www.hindawi.com
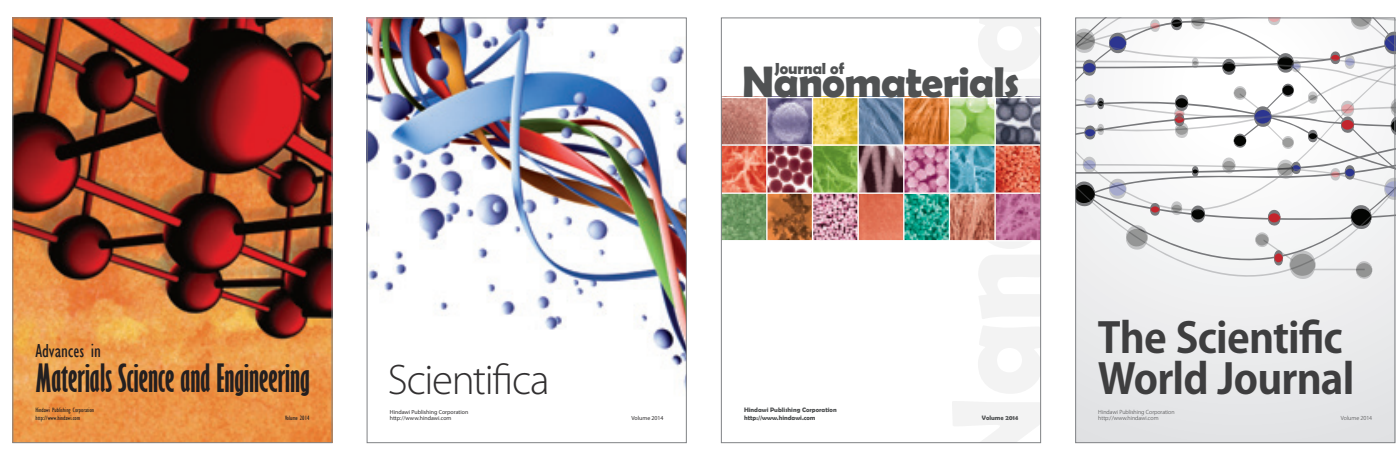

\section{The Scientific World Journal}
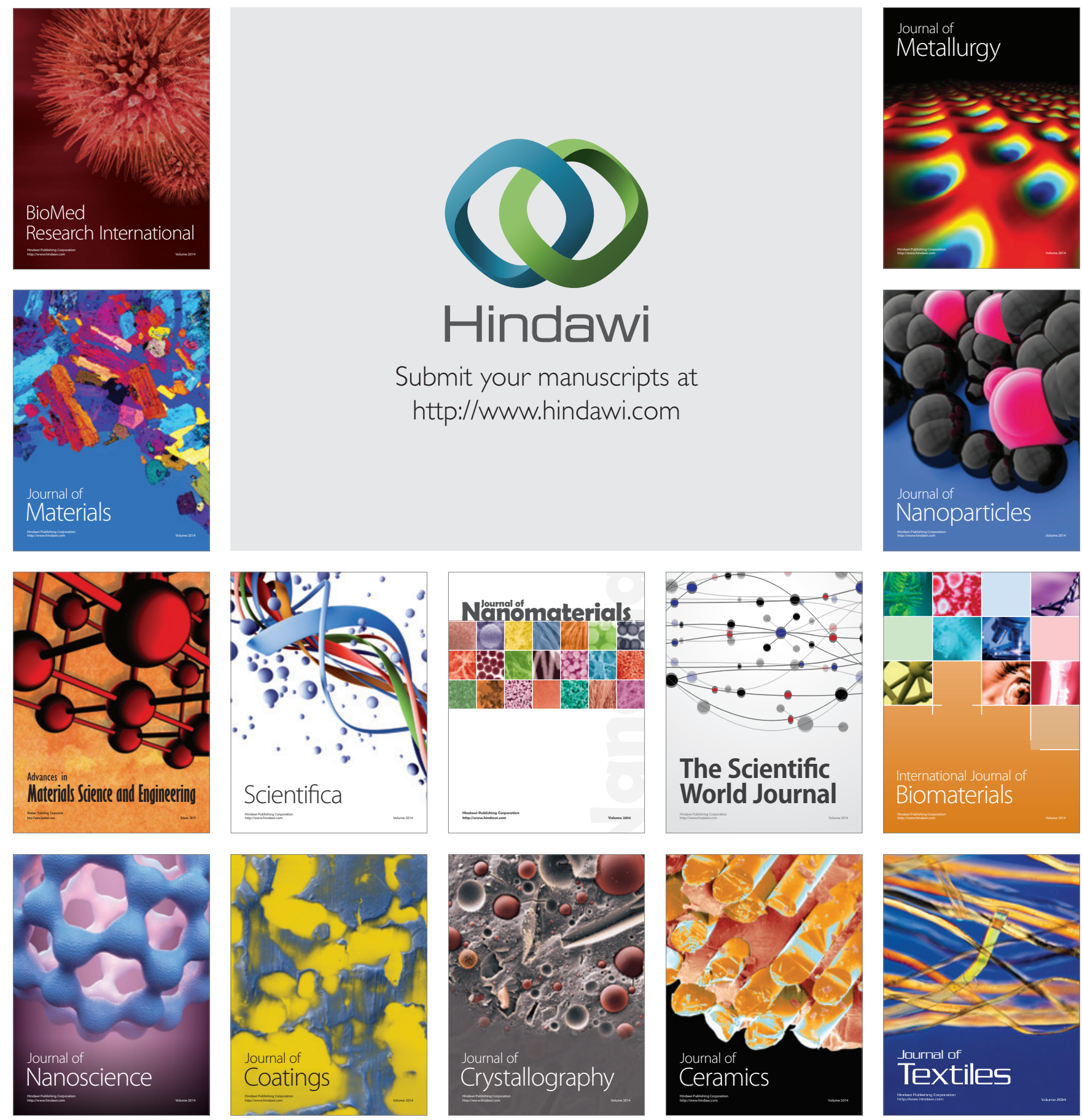